\title{
Treatment patterns and real-world evidence for stage III non-small cell lung cancer in Central and Eastern Europe
}

\author{
Milada Zemanova1 ${ }^{1}$ Marko Jakopovic ${ }^{2}$, Karmen Stanic ${ }^{3,4}$, Małgorzata Łazar-Poniatowska ${ }^{5}$, \\ Martina Vrankar ${ }^{3,4}$, Petronela Rusu', Tudor Ciuleanu6, Davorin Radosavljevic ${ }^{7}$, \\ Krisztina Bogos $^{8}$, Sergiusz Nawrocki ${ }^{9}$ \\ ${ }^{1}$ 1st Faculty of Medicine of Charles University, Prague, Czech Republic \\ ${ }^{2}$ Department for Respiratory Diseases Jordanovac, University Hospital Centre Zagreb, School of Medicine, \\ University of Zagreb, Zagreb, Croatia \\ ${ }^{3}$ Institute of Oncology Ljubljana, Ljubljana, Slovenia \\ ${ }^{4}$ Faculty of Medicine, University of Ljubljana, Ljubljana, Slovenia \\ ${ }^{5}$ Department of Oncology and Radiotherapy, Medical University of Gdansk, Gdansk, Poland \\ ${ }^{6}$ Institute of Oncology "Prof. Dr. Ion Chiricuta”, Cluj-Napoca, Romania \\ 7 Institute for Oncology and Radiology of Serbia, Belgrade, Serbia \\ ${ }^{8}$ National Koranyi Institute of TB and Pulmonology, Budapest, Hungary \\ ${ }^{9}$ Department of Oncology, University of Warmia and Mazury in Olsztyn, Olsztyn, Poland
}

Radiol Oncol 2020; 54(4): 447-454.

Received 9 June 2020

Accepted 10 July 2020

Correspondence to: Assist. Prof. Karmen Stanič, P.D., Ph.D., Institute of Oncology Ljubljana, Zaloška 2, 1000 Ljubljana, Slovenia. E-mail: kstanic@onko-i.si

Disclosure: Dr. Zemanova reports other from AstraZeneca, during the conduct of the study; grants from AstraZeneca, grants and personal fees from BristolMyersSquibb, personal fees from Boehrinegr Ingelheim, personal fees from MSD, personal fees from Roche, grants from Novartis, outside the submitted work; Dr. Jakopovic reports personal fees and non-financial support from AstraZeneca, personal fees and non-financial support from Roche, personal fees and non-financial support from MSD, personal fees and non-financial support from Pfizer, personal fees and non-financial support from Boehringer Ingelheim, outside the submitted work; Dr. Stanic reports personal fees and nonfinancial support from AstraZeneca, during the conduct of the study; Dr. Vrankar reports personal fees from AstraZeneca, Roche, Boehringer Ingelheim, Merck Sharp \& Dohme, other from AstraZeneca, Roche, Boehringer Ingelheim, outside the submitted work; Dr. Rusu reports personal fees from AstraZeneca, personal fees from AD-pharma, outside the submitted work; Dr. Ciuleanu reports consultancy fees from Astellas, Janssen, Bristol-Myers Squibb, Merck Serono, Amgen, Roche, Pfizer, Boehringer Ingelheim, Lilly, AstraZeneca, MSD, Sanofi, Novartis, Servier, AD Pharma; Dr. Radosavljevic reports personal fees and non-financial support from Astra Zeneca, personal fees and non-financial support from MSD, personal fees and non-financial support from Roche, personal fees and non-financial support from Pfizer, personal fees from Boerhinger Ingelheim, personal fees and non-financial support from Merck, personal fees and non-financial support from Amicus, outside the submitted work; other authors have nothing to disclose.

Background. The aim of this project was to collect real-world evidence and describe treatment patterns for stage III non-small cell lung cancer in Central and Eastern Europe. Based on real-world evidence, an expert opinion was developed, and the unmet needs and quality indicators were identified.

Patients and methods. A systematic literature search and a multidisciplinary expert panel of 10 physicians from 7 countries used a modified Delphi process to identify quality indicators and unmet needs in patients with stage III non-small cell lung cancer. The profound questionnaire was used to characterize treatment patterns used for stage III non-small cell lung cancer, and a systematic review identified patterns in Central and Eastern Europe. The first questionnaire was completed by a group of medical oncologists, radiation oncologists and pneumologists. The panel of experts attended an in-person meeting to review the results of the questionnaire and to process a second round Delphi. An additional survey was then compiled and completed by the panel.

Results. A complete consensus was reached by the panel of experts on a set of evidence-based clinical recommendations. The experience-based questionnaire generated a highly variable map of treatment patterns within the region. A list of unmet needs and barriers to quality care were developed with near-unanimous consent of the panel of experts. Conclusions. The current landscape of diagnostic and therapeutic approaches in Central and Eastern European countries is highly variable. We identified several significant barriers, mainly related to the availability of diagnostic and imaging methods and low rates of chemoradiotherapy with curative intention as initial treatment for unresectable stage III NSCLC.

Key words: stage III non-small cell lung cancer; treatment patterns; Delphi method; quality of care; expert panel; real-world evidence 


\section{Introduction}

Lung cancer is the leading cause of cancer mortality worldwide, with over 2 million newly diagnosed cases annually. Lung cancer constituted $11.6 \%$ of all cancer cases diagnosed in 2018, according to the International Agency for Research on Cancer and worldwide numbers are still rising. ${ }^{1}$ There were over 1.8 million deaths caused by lung cancer in 2018. ${ }^{1}$ In Central and Eastern Europe (CEE) ${ }^{2}$, the lung cancer incidence was almost 150,000 newly diagnosed cases in 2018, with over 131,000 deaths caused by lung cancer in the region. ${ }^{3}$

The most common form of lung cancer is nonsmall cell lung cancer (NSCLC), accounting for $80 \%-85 \%$ of all cases. ${ }^{4}$ Stage III non-small cell lung cancer comprises approximately one-third of NSCLC patients and is very heterogeneous with a variable, although mostly poor, prognosis. ${ }^{4}$ Due to its heterogeneity, a general schematic management approach is not appropriate and is recommended that the decision about the treatment is reached through multidisciplinary tumor board. Usually, a combination of local therapy with systemic platinum-based doublet chemotherapy and, recently added, immune therapy is used. ${ }^{4}$

According to the TNM 8 staging system, stage III NSCLC is subclassified into stage IIIA, IIIB, and IIIC. ${ }^{5,6}$ Lung cancer symptoms occur mostly late in the disease, so the majority of patients with NSCLC present with advanced metastatic disease that is incurable with currently available therapy, therefore, patient prognosis is critically dependent on early diagnosis and early treatment.

European Society for Medical Oncology (ESMO) guidelines, which were updated in 2017, directs the treatment of locally advanced NSCLC as follows: concurrent chemoradiotherapy is considered the preferred treatment for patients who are in good condition in stage IIIA, IIIB and IIIC. If chemoradiotherapy is not possible, then sequential chemotherapy followed by definitive radiotherapy represents a valid and effective alternative. ${ }^{7}$ Results from the PACIFIC trial show improvement in overall survival (OS) and progression-free survival (PFS) using a combination of chemoradiotherapy and immunotherapy (represented by durvalumab in this case). ${ }^{8,9}$ In this randomized trial, the 36 -month OS rate was $57.0 \%$ in the durvalumab group and $43.5 \%$ in the placebo group. ${ }^{10}$ PFS was reported as a median duration of 17.2 months in the durvalumab group and 5.6 months in the placebo group $(\mathrm{p}<0.001)$ according to the study report from $2018 .{ }^{9}$
Real-world data on treatment patterns of locally advanced NSCLC in CEE are limited. Therefore, we aimed to:

1. Generate a real-world matrix on treatment patterns in CEE based on an extensive literature search.

2. Generate a summary of treatment patterns used in stage III NSCLC in CEE based on clinical practice, find the main barriers to treatments, and formulate a set of quality of care indicators.

3. Develop a consensus on evidence-based clinical recommendations for Stage III NSCLC in CEE in cooperation with a panel of experts (henceforth referred to as the expert panel $[\mathrm{EP}])$ from the region.

The Delphi method was used as a technique for consensus development.

\section{Patients and methods}

\section{Study design}

The study consisted of five parts: (1) an extensive literature search with a focus on real-world evidence (RWE); (2) development of a questionnaire; (3) selection of an expert panel; (4) an online survey; and (5) analyzing and discussing the results during the expert panel meeting. This study consisted of a survey of expert opinions, and no patient data were collected, so no specific independent ethical approval was necessary.

\section{Expert panel}

The expert panel was composed of 10 members from CEE countries, including Croatia, Czech Republic, Hungary, Poland, Romania, Serbia, and Slovenia. Due to the multidisciplinary nature of NSCLC therapy, representatives from a variety of disciplines were nominated to be on the expert panel, which ultimately consisted of medical oncology, radiation oncology and pneumology. Each of the panelists was an authority in the particular area of expertise in her or his country.

\section{Literature search}

Web of Science, PubMed, and the Cochrane library were thoroughly searched. A total of ten hits was considered relevant, and from those, a map of treatment patterns in CEE was generated. The goal was to identify synthesized research evidence 
TABLE 1. List of real-world evidence literature from the Central and Eastern Europe region

\begin{tabular}{|c|c|c|c|c|c|}
\hline Authors & $\begin{array}{l}\text { Type of study, } \\
\text { country }\end{array}$ & Treatment & $\begin{array}{l}\text { Stages of } \\
\text { NSCLC }\end{array}$ & Type of cancer & Population \\
\hline $\begin{array}{l}\text { Zemanová et al., } \\
2020^{18}\end{array}$ & $\begin{array}{l}\text { Registry, Czechia, } \\
\text { Austria, Latvia, Serbia, } \\
\text { Hungary, Poland }\end{array}$ & $\begin{array}{l}\text { Surgery 23\%, } \\
\text { RT 55\%, } \\
\text { CT } 80 \%\end{array}$ & $\begin{array}{l}\text { IIIA } 55 \% \\
\text { IIIB } 45 \%\end{array}$ & $\begin{array}{l}\text { Squamous } 53 \% \text {, } \\
\text { adenoc. } 38 \% \text {, } \\
\text { not specified } 6 \% \text {, } \\
\text { other } 3 \%\end{array}$ & 583 p., $78 \%$ males \\
\hline $\begin{array}{l}\text { Vrankar et al., } \\
2018^{22}\end{array}$ & Observational, Slovenia & $\begin{array}{l}\text { Induction CT in } \\
3 \text { cycles, + CCRT, } \\
2 \text { cycles }\end{array}$ & $\begin{array}{l}\text { IIIA } 57 \% \text {, } \\
\text { IIIB } 43 \%\end{array}$ & $\begin{array}{l}\text { Squamous } 58 \% \text {, } \\
\text { adenoc. } 22 \% \text {, } \\
\text { large cell } 6 \% \text {, } \\
\text { other } 14 \%\end{array}$ & 102 p., $79 \%$ males \\
\hline $\begin{array}{l}\text { Podmaniczky et } \\
\text { al., } 2015^{24}\end{array}$ & Observational, Hungary & $\begin{array}{l}\text { Platinum-based } \\
\text { neoadjuvant CT }\end{array}$ & $\begin{array}{l}\text { IIIA 60\%, } \\
\text { IIIB 20\% }\end{array}$ & $\begin{array}{l}\text { Squamous } 59 \% \text {, } \\
\text { adenoc. } 41 \%\end{array}$ & 46 p., $63 \%$ males \\
\hline $\begin{array}{l}\text { Jeremic, } \\
2015^{25}\end{array}$ & Review, Serbia & $\begin{array}{l}\text { Standard treatment } \\
\text { options }\end{array}$ & NA & NA & NA \\
\hline $\begin{array}{l}\text { Georgieva el at., } \\
2014^{26}\end{array}$ & Observational, Bulgaria & NA & $\begin{array}{l}\text { III } 2.4 \% \\
\text { IIIA } 12 \% \\
\text { IIIB } 2.4 \%\end{array}$ & $\begin{array}{l}\text { Squamous } 22 \% \text {, } \\
\text { adenoc. } 55 \% \text {, non- } \\
\text { small } 14 \% \text {, other } 10 \%\end{array}$ & 42 p., $57 \%$ males \\
\hline $\begin{array}{l}\text { Kolodziejczyk et al., } \\
2011^{28}\end{array}$ & $\begin{array}{l}\text { Prospective study, } \\
\text { Poland }\end{array}$ & $\begin{array}{l}\text { Radical RT, } \\
\text { neoadjuvant CT } 46 \%\end{array}$ & $\begin{array}{l}\text { IIIA 31\%, } \\
\text { IIIB 39\% }\end{array}$ & $\begin{array}{l}\text { Squamous } 41 \% \text {, } \\
\text { adenoc. } 8 \% \text {, } \\
\text { large cell } 2 \% \text {, } \\
\text { no specification } 45 \% \text {, } \\
\text { no histology } 4 \%\end{array}$ & 100 p., $78 \%$ males \\
\hline $\begin{array}{l}\text { Jeremic et al., } \\
2011^{29}\end{array}$ & Toxicity studies, Serbia & CCRT & NA & NA & $600 \mathrm{p}$. \\
\hline $\begin{array}{l}\text { Kepka et al., } \\
2011^{30}\end{array}$ & Observational, Poland & Surgery, RT, CT & NA & NA & $291 \mathrm{p}$. \\
\hline
\end{tabular}

$\mathrm{CCRT}=$ concurrent chemoradiotherapy; $\mathrm{CT}=$ chemotherapy; $\mathrm{NA}=$ not available; $\mathrm{NSCLC}=$ non-small cell lung cancer; $\mathrm{p}$. = patients; $\mathrm{RT}=$ radiotherapy

including clinical practice, systematic reviews, meta-analyses, and conference proceedings. Articles were included in the RWE map if they were fully published in English.

\section{Online survey}

The online expert questionnaire was divided into three parts. These parts covered expert experiences in diagnosis, therapy, and organization of the care of patients with stage III NSCLC. The expert panel members entered the rates of utilization in each category or other specific counts according to clinical practice in their medical center. Some of the outcomes, e.g. the number of specialized oncology centers in the country, were determined as counts in the country of panelists.

\section{Delphi panel}

The Delphi technique is a method for collecting data from respondents within their domain of expertise. ${ }^{11}$ The aim is to achieve a convergence of opinion on a specific medical issue (in this case, NSCLC stage III therapy). There have been sev- eral published cases using the Delphi method to study lung cancer. ${ }^{12-17}$ The consensus part of the study was carried out using a modified Delphi method. The first round of the Delphi consensus was built as a set of 12 evidence-based recommendations extracted from ESMO clinical guidelines. ${ }^{7}$ Responses were collected on a 5-point Likert scale. In the $1^{\text {st }}$ round, each panelist responded using the following answers: (1) strongly disagree; (2) basically disagree; (3) doubtful; (4) basically agree; or (5) strongly agree. A Delphi consensus was reached when the mean of all values was $>4.0$. If the mean of all values was 5.0, the consensus was considered unanimous. All statements then underwent a second Delphi round. The second Delphi round was held as an in-person meeting, and all 12 statements were discussed. In the meeting, it was possible to vote for or against each statement. A consensus was defined as $>80 \%$ of the responses were in favor of the statement. The overall decision was then distributed via email for any subsequent comments by the expert panel. A total of nine panelists responded to the first round and ten panelists responded to the second round. The first round took place from November 11-23, 2019 and 
was performed via an online survey. The second round took place in Prague, Czech Republic, on November 29, 2019.

\section{Statistical analysis}

Descriptive analytical methods were used to analyze continuous and categorical variables. Continuous variables were reported as mean, standard deviation, minimum, and maximum. Categorical variables were reported as count and rate. MS Excel was used for the analysis.

\section{Manuscript preparation}

Based on the input of expert panel, the draft manuscript was prepared by medical writing agency. This project began in August 2019 and ended in March 2020. During the drafting of the article, newly published literature was reviewed to analyze the clinical implications of any new data in patients with stage III NSCLC.

\section{Results}

\section{A literature search of RWE in CEE}

There was a limited number of RWE-based literature on population diagnosed with stage III NSCLC from the CEE region. Table 1 presents a list of analyzed literature from 2011-2020. This includes data on patient registries and observational and toxicity studies. The only relevant literature with the texts written completely in English related to Bulgaria, Czech Republic, Hungary, Poland, Slovenia and Serbia. Mostly, these publications presented data on treatment, diagnostic methods and staging.

\section{Treatment patterns based on clinical experience}

Table 2 presents the data collected in the area of staging and diagnosis of stage III NSCLC. Concerning the staging of NSCLC, $32 \%( \pm 13 \%)$ of NSCLC patients in any particular medical center were diagnosed with stage III NSCLC, and most of those were in stage IIIB $(45 \% \pm 12 \%)$. Good consistency in the field of imaging was observed. The most common diagnostic procedures, i.e. X-Ray, chest computed tomography (CT) (including the CT of upper abdomen area), and bronchoscopy, were provided to at least $93 \%$ of patients with stage III NSCLC. Differences in the percentages of treated patients who received abdominal CT, brain $\mathrm{CT}$, en-
TABLE 2. Patterns in stage III non-small cell lung cancer diagnosis in Central and Eastern Europe region; \% of patients treated in the medical center of particular panelists

\begin{tabular}{|c|c|c|c|}
\hline & $\mathbf{N}$ & Mean $( \pm S D)$ & Min-Max \\
\hline \multicolumn{4}{|l|}{ Staging } \\
\hline All stage III & 9 & $32 \%( \pm 13 \%)$ & $20 \%-65 \%$ \\
\hline Stage IIIA & 9 & $37 \%( \pm 14 \%)$ & $20 \%-60 \%$ \\
\hline Stage IIIB & 9 & $45 \%( \pm 12 \%)$ & $30 \%-60 \%$ \\
\hline Stage IIIC & 9 & $18 \%( \pm 11 \%)$ & $6 \%-40 \%$ \\
\hline \multicolumn{4}{|l|}{ Imaging } \\
\hline X-Ray & 9 & $99 \%$ ( $\pm 3 \%)$ & $90 \%-100 \%$ \\
\hline Chest CT & 9 & $98 \%$ ( $\pm 4 \%)$ & $90 \%-100 \%$ \\
\hline Abdominal CT & 9 & $87 \%( \pm 19 \%)$ & $50 \%-100 \%$ \\
\hline Brain CT & 9 & $58 \%( \pm 33 \%)$ & $12 \%-100 \%$ \\
\hline Bronchoscopy & 9 & $93 \%( \pm 10 \%)$ & $75 \%-100 \%$ \\
\hline EBUS & 9 & $37 \%$ ( $\pm 29 \%)$ & $9 \%-80 \%$ \\
\hline PET-CT & 9 & $54 \%( \pm 30 \%)$ & $20 \%-80 \%$ \\
\hline Bone scan & 9 & $15 \%( \pm 16 \%)$ & $0 \%-40 \%$ \\
\hline Brain MRI & 9 & $14 \%( \pm 7 \%)$ & $2 \%-20 \%$ \\
\hline \multicolumn{4}{|l|}{ Biomarkers } \\
\hline PD-L1 reflex testing & 9 & $50 \%( \pm 40 \%)$ & $2 \%-100 \%$ \\
\hline PD-L1 results available* & 9 & $56 \%( \pm 31 \%)$ & $2 \%-100 \%$ \\
\hline
\end{tabular}

dobronchial ultrasound (EBUS), and PET-CT were evaluated. Bone scans and brain MRIs were provided at lower rates to patients $(14 \%-15 \%)$. Also, PD-L1 was tested at various rates within the CEE. The mean rate of patients undergoing the PD-L1 reflex testing was $50 \%( \pm 40 \%)$. The mean rate of available PD-L1 results was $56 \%( \pm 31 \%)$, as proportion of patients was tested on demand.

The most heterogeneous set of responses was obtained for the descriptions of initial patient therapy, which reflects high variability in treatment approaches across the region (Table 3). About two-thirds of patients initially received radical treatment, and a mean of $30 \%$ of patients were treated palliative. When looking at the initial radical treatment modalities, with the intention to cure, showed that clinical practice was heterogeneous from country to country, and even individual clinical centers within countries had their own approach. As reported, in mean, chemotherapy alone was administered in $13 \%$ and cumulatively, concurrent and sequential chemoradiotherapy was ad- 
ministered in more than $50 \%$ of patients in mean. Palliative radiotherapy was provided in $60 \%$ of patients intended for palliative treatment.

Table 4 describes how the care of patients with stage III NSCLC is organized. Usually, the first contact physician is a general practitioner $(54 \% \pm$ $27 \%)$ or a pneumologist $(35 \% \pm 29 \%)$. Other, less common, first contact variants included other professionals such as medical oncologists and radiation oncologists. In four out of nine countries lung cancer patients are referred to specialized oncology centers, where the patient has access to innovative oncology treatment options, while in other five countries, lung cancer is treated in local hospitals. The number of specialized oncology centers per country varies from 3 to 50 , according to the population size of the particular country. Most respondents $(89 \%)$ reported that patients diagnosed with stage III of NSCLC were referred to a multidisciplinary team. In most cases, medical oncologist is supervising the follow-up after initial therapy for unresectable stage III patients.

\section{Evidence-based clinical recommendations}

Table 5 shows the level of consensus for the twelve evidence-based clinical recommendations relative to stage III NSCLC. There was a high level of consensus and sometimes even unanimity with many of the twelve statements.

\section{Main barriers and quality indicators}

Table 6 presents the final list of the main barriers to treatment of stage III NSCLC identified and consensually agreed on by the expert panel. Rates of chemoradiotherapy (CRT) are low due to the long waiting times for radiotherapy and especially for advanced radiotherapy techniques. The reason for the low CRT rates could also be caused by providing radiotherapy and chemotherapy in different institutions. Another barrier is a long referral process among different physician specialties. Next, awareness of lung cancer symptoms, risk factors, and treatment options among patients is affected by health literacy and the influence of social status. Finally, late access to diagnostic and imaging procedures is also combined with long waiting times and low capacity.

The list of the agreed quality of care indicators is presented in Table 7. The proportion of patients treated with chemoradiotherapeutic radical treatment intention was described as the most signifi-
TABLE 3. Patterns in stage III non-small cell lung cancer diagnosis therapy; \% of patients treated in the medical center of the particular panelist

\begin{tabular}{lccc}
\hline & N & Mean ( \pm SD) & Min-Max \\
\hline Initial treatment & 9 & $70 \%( \pm 20 \%)$ & $30 \%-96 \%$ \\
\hline Radical treatment & 9 & $30 \%( \pm 20 \%)$ & $4 \%-70 \%$ \\
\hline $\begin{array}{l}\text { Palliative treatment } \\
\text { Radical treatment }\end{array}$ & 9 & $17 \%( \pm 6 \%)$ & $10 \%-25 \%$ \\
\hline Surgery & 8 & $13 \%( \pm 16 \%)$ & $0 \%-48 \%$ \\
\hline Chemotherapy & 8 & $15 \%( \pm 9 \%)$ & $5 \%-25 \%$ \\
\hline Radiotherapy & 8 & $21 \%( \pm 12 \%)$ & $0 \%-30 \%$ \\
\hline Concurrent chemoradiotherapy & 8 & $34 \%( \pm 14 \%)$ & $18 \%-50 \%$ \\
\hline Sequential chemoradiotherapy & 8 & & \\
\hline Palliative treatment & 8 & $60 \%( \pm 33 \%)$ & $3 \%-90 \%$ \\
\hline Palliative radiotherapy & 8 & $29 \%( \pm 24 \%)$ & $10 \%-80 \%$ \\
\hline Best supportive care & & & \\
\hline
\end{tabular}

TABLE 4. Patterns in stage III non-small cell lung cancer diagnosis organization of care; $\%$ of patients treated in the medical centers of particular panelists

\begin{tabular}{lccc}
\hline First contact physician & N & Mean ( \pm SD) & Min-Max \\
\hline General practitioner & 9 & $54 \%( \pm 27 \%)$ & $20 \%-90 \%$ \\
Pneumologist & 9 & $35 \%( \pm 29 \%)$ & $10 \%-95 \%$ \\
\hline Medical oncologist & 9 & $9 \%( \pm 13 \%)$ & $0 \%-30 \%$ \\
\hline Radiation oncologist & 9 & $3 \%( \pm 5 \%)$ & $0 \%-10 \%$ \\
Other & 9 & $5 \%( \pm 5 \%)$ & $0 \%-10 \%$ \\
\hline
\end{tabular}

cant indicator of quality of care, followed by the improved survival over time.

\section{Discussion}

The main scope of the project was to explore the treatment patterns in stage III NSCLC in the CEE region since the current information on this topic is very limited. Data were gathered through a systematic literature search, an online survey of leading experts, and a modified Delphi consensus. It should be noted that the abovementioned data on treatment patterns represent the particular medical centers associated with the respondents and that situations in particular countries could differ slightly.

The literature search generated a limited amount of real-world data from the CEE region and only represented a subset of the countries participating in the study. This is mainly because most of the 
TABLE 5. Evidence based clinical recommendations consensus

\begin{tabular}{|c|c|c|c|}
\hline \multicolumn{2}{|c|}{ Statement } & \multirow{2}{*}{$\begin{array}{c}1^{\text {st }} \text { round } \\
\text { average } \\
\mathrm{N}=9 \\
4.8\end{array}$} & \multirow{2}{*}{$\begin{array}{c}\begin{array}{c}\text { Final } \\
\text { consensus }\end{array} \\
\text { Consensus }\end{array}$} \\
\hline 1. & $\begin{array}{l}\text { All patients planned for stage III NSCLC treatment should undergo a diagnostic contrast-enhanced CT scan of } \\
\text { the chest and upper abdomen followed by a PET or a combined PET-CT using a CT technique with adequately } \\
\text { high resolution for initial staging purposes. }\end{array}$ & & \\
\hline 2. & All patients planned for curative stage III NSCLC treatment should receive brain imaging for initial staging. & 4.8 & Consensus \\
\hline 3. & Concurrent CRT is the treatment of choice in patients evaluated as unresectable in stage IIla, IIIb, and Illc. & 4.6 & Consensus \\
\hline 5. & $\begin{array}{l}\text { An experienced multidisciplinary team is of paramount importance in any complex multimodality treatment } \\
\text { strategy decision. }\end{array}$ & 4.9 & Consensus \\
\hline 6. & $\begin{array}{l}\text { In the absence of contraindications, the optimal ChT to be combined with radiation in stage III NSCLC should } \\
\text { be platinum-based therapy. }\end{array}$ & 4.3 & Consensus \\
\hline 7. & $\begin{array}{l}\text { When delivered perioperatively, platinum-based combinations are considered the treatment of choice, in the } \\
\text { absence of contraindications. }\end{array}$ & 4.6 & Consensus \\
\hline 8. & In the stage III disease CRT strategy, two to four cycles of concomitant ChT should be delivered. & 4.9 & Consensus \\
\hline 11. & In sequential approaches, RT delivered over a short overall treatment time is recommended. & 4.3 & Consensus \\
\hline 12. & $\begin{array}{l}\text { Adjuvant anti PD-L1 checkpoint inhibitor durvalumab is indicated for unresectable NSCLC with PD-L1 } \geq 1 \% \\
\text { without progression after chemoradiotherapy with a platinum-based regime. }\end{array}$ & 5.0 & Unanimity \\
\hline
\end{tabular}

ChT = chemotherapy; CRT = chemoradiotherapy; $\mathrm{CT}=$ computed tomography; NSCLC = non-small cell lung cancer; $\mathrm{PET}$-CT = positron emission tomography-computed tomography; $\mathrm{RT}$ = radiotherapy

TABLE 6. Main barriers in the treatment of stage III non-small cell lung cancer found by our panel of experts

\begin{tabular}{ll}
\hline Main barriers \\
\hline $\begin{array}{l}\text { Low chemoradiotherapy rates due to long waiting } \\
\text { times for radiotherapy, especially for advanced RT } \\
\text { techniques and/or radiotherapy and chemotherapy } \\
\text { performed by different institutions. }\end{array}$ \\
$\begin{array}{l}\text { Long referral process among different specialities } \\
\text { (general practitioner, pneumologist, medical } \\
\text { oncologist, radiotherapist). }\end{array}$ \\
3. $\begin{array}{l}\text { Poor health literacy and social status of patients } \\
\text { influence awareness of lung cancer symptoms, risk } \\
\text { factors and treatment. }\end{array}$ \\
4. $\begin{array}{l}\text { Late access to imaging and diagnostic procedures, } \\
\text { especially PET-CT - long waiting times, low capacity. }\end{array}$ \\
5. $\begin{array}{l}\text { Barriers to implementing targeted population } \\
\text { screening programs. }\end{array}$ \\
\hline
\end{tabular}

PET-CT = positron emission tomography-computed tomography: $\mathrm{RT}=$ radiotherapy

published data were not published in English or in the indexed literature. It is worth noting that much of the literature was published in recent years, which may reflect the availability of new therapeutic modalities.

A comparison of the expert panel consensus with the ESMO guidelines and the current practice in staging, diagnosis, and treatment of stage III NSCLC revealed differences. ${ }^{7}$ This fact was well described in the survey of the main barri-
TABLE 7. Quality of care indicators in stage III non-small cell lung cancer found by our panel of experts

\section{Quality of care indicators}

1. The proportion of patients treated with

. chemoradiotherapy in radical treatment intention.

2. Improved survival (median OS, 5 years survival) over time.

Time from first symptoms to first contact with a lung

3. cancer specialist, time from first contact with a lung cancer specialist to first treatment.

The proportion of patients with full histopathological/

4. molecular confirmation of the diagnosis - PET-CT, brain imaging, PD-L1.

5. The proportion of treatment decisions confirmed by 5. a multidisciplinary team.

OS = overall survival; $\mathrm{PET}-\mathrm{CT}=$ positron emission tomography-computed tomography

ers and quality of care indicators among the panelists. There was great agreement regarding the evidence-based recommendations extracted from ESMO clinical guidelines in the treatment of stage III NSCLC, even though the experience-based survey revealed considerable differences in current treatment patterns. The list of quality of care indicators produced by the expert panel agreed in part with the list produced in other countries (e.g., the United Kingdom and China), especially with 
regard to the proportions of patients intended to various treatments or histopathological diagnostic procedures, but our list also proposed several new indicators relative to the decision making role of multidisciplinary teams. ${ }^{14,16}$ Expert panel agreed a new era for unresectable stage III NSCLC patients in CEE is coming and expert panel agreed to reevaluate the 1-2 year the treatment improvement based on the indicators.

Significantly, our survey found a great deal of heterogeneity in therapy organization and treatment modalities offered (available) in different medical centers within CEE. The heterogeneity was found in almost all parts of the survey, excluding consent rates of patients in long-term established diagnostic procedures such as X-Ray and CT. The more specific the procedure, e.g., histopathological diagnostic procedures, the greater the variance in rates of utilization in patients. It is agreed, that reflex PD-L1 testing and brain MRI rates should be improved. Moreover, patterns of initial radical treatment showed great variability among the panelists. This fact was also observed in a recent publication by Zemanová et al., which mapped these patterns in the same region. ${ }^{18}$ It is important to focus on improving the rates of chemoradiotherapy provided to patients. Yet in 2007, the positive impact of concurrent chemoradiotherapy with vinorelbine and platinum based compounds followed by consolidation chemotherapy was proven by Rusu et al. ${ }^{19}$ This study reported a 15 months median OS in patients with stage III NSCLC and well tolerability of the treatment.

Importantly, the expert panel unanimously agreed that adjuvant anti PD-L1 checkpoint inhibitor durvalumab is indicated for unresectable NSCLC with PD-L1 $\geq 1 \%$ without progression after chemoradiotherapy with a platinum-based regime (Table 5). Chemoradiotherapy followed by the immunotherapy is new standard of care according to the National Comprehensive Cancer Network (NCCN) guidelines and The National Institute for Health and Care Excellence (NICE) guidance. ${ }^{20,21}$ Improving the chemoradiotherapy rates, PD-L1 testing and gaining access to durvalumab are the next needed steps to be implemented in CEE in order to treat the stage III unresectable patients according to new standard of care.

\section{Conclusions}

The current landscape of diagnostic and therapeutic approaches in CEE countries is highly variable, and relevant real-world data are missing. We identified several significant barriers, mainly related to the availability of diagnostic and imaging methods and low rates of chemoradiotherapy with curative intention as initial treatment for unresectable stage III NSCLC. Improving CRT rates will also enable consolidative treatment with durvalumab to further improve the OS of stage III unresectable patient population.

The way forward will involve an agreement to establish a set of quality of care indicators with routine monitoring and assessment within the clinical practice framework. The panel of experts agreed on future monitoring of improvement in the standards of care for stage III unresectable NSCLC.

\section{Acknowledgements}

This manuscript presents independent work of the expert panel. The views and opinions expressed by authors in this publication are those of the authors and do not necessarily reflect the overall situation in specific country.

The project was funded by AstraZeneca for logistical and medical writing support.

Tina Jerič, M. Pharm. and Lenka Mikasová, Ph. D. of AstraZeneca contributed to the project design and participated at the expert panel meeting.

Medical writing support, which was in accordance with good publication practice guidelines, was provided by Tomaš Doležal and Tereza Tumova, of Value outcomes (Prague, Czech Republic).

\section{References}

1. International Agency for Research on Cancer. World Health Organization. Press release N. 263. [cited 2020 Feb 13]. Available at: https://www.who. int/cancer/PRGlobocanFinal.pdf

2. Publications Office of the EU. Central and Eastern Europe. [cited 2020 Feb 14]. Available at: https://op.europa.eu/en/web/eu-vocabularies/thconcept/-/resource/eurovoc/914

3. International Agency for Research on Cancer. World Health Organization. Lung cancer. [cited 2020 Feb 15]. Available at: https://gco.iarc.fr/today/ data/factsheets/cancers/15-Lung-fact-sheet.pdf

4. Huber RM, Ruysscher DD, Hoffmann H, Reu S, Tufman A. Interdisciplinary multimodality management of stage III nonsmall cell lung cancer. Eur Respir $\operatorname{Rev} 2019$; 28: 190024. doi: 10.1183/16000617.0024-2019

5. Detterbeck FC, Boffa DJ, Kim AW, Tanoue LT. The eighth edition lung cancer stage classification. Chest 2017; 151: 193-203. doi: 10.1016/j. chest.2016.10.010

6. Goldstraw P, Chansky K, Crowley J, Rami-Porta R, Asamura H, Eberhardt WEE, et al. The IASLC Lung Cancer Staging Project: proposals for revision of the TNM stage groupings in the forthcoming (eighth) edition of the TNM classification for lung cancer. J Thorac Oncol 2016; 11: 39-51. doi: 10.1016/j. jtho.2015.09.009 
7. Postmus PE, Kerr KM, Oudkerk M, Senan S, Waller DA, Vansteenkiste J, et al. Early and locally advanced non-small-cell lung cancer (NSCLC): ESMO Clinical Practice Guidelines for diagnosis, treatment and follow-up. Ann Oncol 2017; 28: iv1-21. doi: 10.1093/annonc/mdx222

8. Antonia SJ, Villegas A, Daniel D, Vicente D, Murakami S, Hui R, et al. Durvalumab after chemoradiotherapy in stage III non-small-cell lung cancer. N Engl J Med 2017; 377: 1919-29. doi: 10.1056/NEJMoa1709937

9. Antonia SJ, Villegas A, Daniel D, Vicente D, Murakami S, Hui R, et al. Overall Survival with Durvalumab after Chemoradiotherapy in Stage III NSCLC. N Engl J Med 2018; 379: 2342-50. doi: 10.1056/NEJMoa1809697

10. Gray JE, Villegas A, Daniel D, Vicente D, Murakami S, Hui R, et al. Three-year overall survival with durvalumab after chemoradiotherapy in Stage III NSCLC - update from PACIFIC. J Thorac Oncol 2020; 15: 288-93. doi: 10.1016/j. jtho.2019.10.002

11. McMillan SS, King M, Tully MP. How to use the nominal group and Delph techniques. Int J Clin Pharm 2016; 38: 655-62. doi: 10.1007/s11096-016 0257-x

12. Isla D, de Castro J, García-Campelo R, Lianes P, Felip E, Garrido P, et al. Treatment options beyond immunotherapy in patients with wild-type lung adenocarcinoma: a Delphi consensus. Clin Transl Oncol 2019; 22: 759-71. doi: 10.1007/s12094-019-02191-y

13. Isla D, González-Rojas N, Nieves D, Brosa M, Finnern HW. Treatment patterns, use of resources, and costs of advanced non-small-cell lung cancer patients in Spain: results from a Delphi panel. Clin Trans/ Oncol 2011; 13: 460-71. doi: 10.1007/s12094-011-0683-0

14. Darling G, Malthaner R, Dickie J, McKnight L, Nhan C, Hunter A, et al Quality indicators for non-small cell lung cancer operations with use of a modified Delphi consensus process. Ann Thorac Surg 2014; 98: 183-90. doi: 10.1016/j.athoracsur.2014.03.001

15. Moldaver D, Hurry M, Evans WK, Cheema PK, Sangha R, Burkes R, et al. Development, validation and results from the impact of treatment evolution in non-small cell lung cancer (iTEN) model. Lung Cancer 2020; 139: 185-94. doi: 10.1016/j.lungcan.2019.10.019

16. Wang X, Su S, Li S, Bao H, Zhang M, Liu D, et al. Development of quality indicators for non-small cell lung cancer care: a first step toward assessing and improving quality of cancer care in China. BMC Cancer 2017; 17: 306 doi: 10.1186/s12885-017-3602-0

17. Provencio M, Carcereny E, Artal Á. Consensus on the use of immune-related response criteria to evaluate the efficacy of immunotherapy in non-small cell lung cancer. Clin Trans/ Oncol 2019; 21: 1464-71. doi: 10.1007/s12094019-02072-4

18. Milada Zemanová, Pirker R, Petruzelka L, Zbozínkova Z, Jovanovic D, Rajer $\mathrm{M}$, et al. Care of patients with non-small-cell lung cancer Stage III - the Central European real-world experience. Radiol Oncol 2020; 54(4): 447 454.; 54: 209-20. doi: 10.2478/raon-2020-0026

19. Rusu P, Ciuleanu TE, Cernea D, Pelau D, Gaal V, Cebotaru C, et al. Concurrent chemoradiotherapy with vinorelbine and a platinum compound followed by consolidation chemotherapy for unresectable stage III non-small cell lung cancer: preliminary results of a phase II study. J BUON 2007; 12: 33-9.

20. National Comprehensive Cancer Network. NCCN Clinical Practice Guidelines in Oncology - Non-Small Cell Lung Cancer. [Internet]. Version 5.2020. [cited 2020 May 27]. Avaiable at: https://www.nccn.org/professionals/physician_gls/pdf/nscl.pdf

21. Durvalumab for treating locally advanced unresectable non-small-cell lung cancer after platinum-based chemoradiation | Guidance | NICE [Internet]. [cited 2020 Feb 27]. Available at: https://www.nice.org.uk/guidance/ta578/ chapter/1-Recommendations

22. Vrankar $M$, Stanic $K$. Long-term survival of locally advanced stage III nonsmall cell lung cancer patients treated with chemoradiotherapy and perspectives for the treatment with immunotherapy. Radiol Oncol 2018; 52 281-8. doi: 10.2478/raon-2018-0009

23. Ramlau R, Krawczyk P, Dziadziuszko R, Chmielewska I, Milanowski J, Olszewski W, et al. Predictors of EGFR mutation and factors associated with clinical tumor stage at diagnosis: Experience of the INSIGHT study in Poland. Oncol Lett 2017; 14: 5611-8. doi: 10.3892/ol.2017.6907

24. Podmaniczky E, Fábián K, Pápay J, Puskás R, Gyulai M, Furák J, et al Decreased ERCC1 Expression After Platinum-Based Neoadjuvant Chemotherapy in non-Small Cell Lung Cancer. Pathol Oncol Res 2015; 21 : 423-31. doi: 10.1007/s12253-014-9839-x
25. Jeremić B. Standard treatment option in stage III non-small-cell lung cancer: case against trimodal therapy and consolidation drug therapy. Clin Lung Cancer 2015; 16: 80-5. doi: 10.1016/j.cllc.2014.08.003

26. Georgieva N, Bochev P, Dancheva Z, Chaushev B, Balev B, Klisarova A, et al. PET/CT in NSCLC with brain metastases. Rentgenol Radiol 2014; 53: 204-10.

27. Zielinski M, Szlubowski A, Kołodziej M, Orzechowski S, Laczynska E, Pankowski J, et al. Comparison of endobronchial ultrasound and/or endoesophageal ultrasound with transcervical extended mediastinal lymphadenectomy for staging and restaging of non-small-cell lung cancer. J Thorac Oncol 2013 ; 8: 630-6. doi: 10.1097/JTO.0b013e318287c0ce

28. Kolodziejczyk M, Kepka L, Dziuk M, Zawadzka A, Szalus N, Gizewska A, et al. Impact of [18F]fluorodeoxyglucose PET-CT staging on treatment planning in radiotherapy incorporating elective nodal irradiation for non-small-cell lung cancer: a prospective study. Int J Radiat Oncol Biol Phys 2011; 80: 1008-14. doi: 10.1016/j.ijrobp.2010.04.018

29. Jeremić B, Miličić B, Milisavljevic S. Toxicity of concurrent hyperfractionated radiation therapy and chemotherapy in locally advanced (stage III) nonsmall cell lung cancer (NSCLC): single institution experience in 600 patients. Clin Transl Oncol 2012; 14: 613-8. doi: 10.1007/s12094-012-0848-5

30. Kepka L, Bujko K, Orlowski TM, Jagiello R, Salata A, Matecka-Nowak M, et al. Cardiopulmonary morbidity and quality of life in non-small cell lung cancer patients treated with or without postoperative radiotherapy. Radiother Oncol 2011; 98: 238-43. doi: 10.1016/j.radonc.2010.09.020 